\title{
ENTRE A ESSENCIALIDADE E A INSTRUMENTALIDADE DO PATRIMÔNIO: VALORES INSTITUCIONAIS E PARTICIPAÇÃO SOCIAL NA GESTÃO DA CONSERVAÇÃO URBANA
}

\author{
Paulo José de Albuquerque Marques da Cunha* \\ Tomás de Albuquerque Lapa* \\ *Instituto Federal de Educação, Ciência e Tecnologia de Pernambuco, Laboratório de Estudos Socioambientais, \\ Garanhuns, PE, Brasil \\ **Universidade Federal de Pernambuco, Programa de Pós-graduação em Desenvolvimento Urbano, Recife, PE, Brasil
}

\begin{abstract}
Resumo
Este artigo insere-se no debate contemporâneo acerca da Gestão da Conservação Urbana baseada nos valores patrimoniais. Em vista da dicotomia entre valores essenciais e valores instrumentais, a Conservação tem encontrado entraves associados às missões das instituições que gerem os sítios patrimoniais e aos processos participativos. Quão efetivos se mostram os mecanismos de gestão compartilhada? Para análise dessa problemática, adota-se o Parque Metropolitano Armando de Holanda Cavalcanti, situado na região Nordeste do Brasil, cuja conservação esbarra no conflito entre residentes e gestores, alcançando resultados insignificantes. Analisam-se o processo de tombamento do Parque e os planos de ações elaborados em 2010 e 2018, com o objetivo de identificar como a participação dos entes relacionados ao bem patrimonial tem contribuído para a tomada de decisão. Para lograr êxito nos processos de conservação, há que se alinhar os discursos com as realidades locais e garantir a efetiva participação dos atores envolvidos.

Palavras-chave

Gestão da Conservação; Conservação Urbana; Valores Patrimoniais; Patrimônio; Participação Social.
\end{abstract}




\title{
BETWEEN THE ESSENTIALITY AND THE INSTRUMENTALITY OF HERITAGE: INSTITUTIONAL VALUES AND SOCIAL PARTICIPATION IN THE MANAGEMENT OF URBAN CONSERVATION
}

\author{
Paulo José de Albuquerque Marques da Cunha* \\ Tomás de Albuquerque Lapa* \\ *Instituto Federal de Educação, Ciência e Tecnologia de Pernambuco, Laboratório de Estudos Socioambientais, \\ Garanhuns, PE, Brazil \\ **Universidade Federal de Pernambuco, Programa de Pós-graduação em Desenvolvimento Urbano, Recife, PE, Brazil
}

\begin{abstract}
This article is part of the contemporary debate about Urban Conservation Management, based on heritage values. In view of the dichotomy between essential and instrumental values, Conservation has encountered obstacles associated with the missions of the institutions that manage heritage sites and participatory processes. How effective are the shared management mechanism? To analyze this issue, the case study of the Metropolitan Park Armando de Holanda Cavalcanti was taken, located in the Northeast Region of Brazil, whose conservation has raised a conflict between residents and managers thus, contributing for insignificant results. It will be analyzed the Park registration process and the action plans prepared in 2010 and 2018, with the purpose of identifying how the participation of entities related to heritage has contributed to the decision-making. For the success of conservation processes, speeches must be aligned with local realities, and ensure the effective participation of all actors involved.

Keywords

Conservation Management; Urban Conservation; Heritage Values; Heritage; Social Participation.
\end{abstract}




\title{
ENTRE A ESSENCIALIDADE E A INSTRUMENTALIDADE DO PATRIMÔNIO: VALORES INSTITUCIONAIS E PARTICIPAÇÃO SOCIAL NA GESTÃO DA CONSERVAÇÃO URBANA
}

\author{
Paulo José de Albuquerque Marques da Cunha \\ Tomás de Albuquerque Lapa
}

Introdução

A abordagem da Gestão da Conservação do patrimônio, baseada em valores, é uma resposta à complexidade dos sítios histórico-culturais e à demanda da sociedade por ações alinhadas com os problemas sociais, econômicos e territoriais locais. A partir de 2013, com a Carta de Burra (AUSTRÁLIA ICOMOS, 2013), a significância cultural de um bem se tornou basilar para os planos de conservação. Cada vez mais, os países têm adotado uma prática de elaboração de planos apoiados em valores, interpretados por meio de processos participativos que envolvem os atores interessados na conservação do bem patrimonial.

O estudo criterioso sobre o papel dos valores tem sido fundamental para a eficácia dos planos de conservação. Para Avrami e Mason (2019, p. 10, tradução nossa), "a dinâmica entre valores e benefícios é complexa e tende ao conflito". Nesse contexto, gerir as mudanças no território, equilibrando a manutenção de valores essenciais do patrimônio e a sua utilização pela sociedade, é ainda um complexo "quebra-cabeça” a ser resolvido pela conservação urbana.

Para minimizar os conflitos, gestores e profissionais da Conservação têm priorizado processos que envolvem maior número de atores interessados no patrimônio. Essa realidade intensificou a "politização dos valores patrimoniais" (AVRAMI; MASON, 2019, p. 10, tradução nossa), deixando o campo da Conservação mais aberto a forças externas, e, ao mesmo tempo, mostrou-se determinante para as mudanças da realidade socioeconômica das localidades. Dito de outra forma, a conservação tem sido instigada a fortalecer a abordagem com base em categorias clássicas de valor (histórico, artístico, cultural e científico), assumindo a influência 
de processos sociais mais amplos como os econômicos, políticos, tecnológicos, urbanos e ambientais.

A Conservação Urbana Integrada caracteriza-se por abordagens distintas e complementares, uma delas centrada na ênfase dos "valores patrimoniais", associados às práticas materialistas e de curadoria, e a outra em "valores sociais”, associados a metas como o desenvolvimento econômico, a consolidação de direitos e a justiça social.

A despeito de ter se tornado bastante evidente nas últimas décadas, na visão de Avrami e Mason (2019) a distinção entre "valor patrimonial e valor social" não deve ser enfatizada, na medida em que a gama de atores envolvidos se ampliou e o patrimônio se revelou útil para diversos grupos. Assim, a distinção não deve ter como intuito desacreditar a prática tradicional, focada nos "valores patrimoniais", nem fragilizar o discurso dos que utilizam os valores sociais com a finalidade de atender a seus interesses. Ao contrário, espera-se alcançar o equilíbrio e a integração entre todos os valores atribuídos aos bens patrimoniais.

Incorporadas pelos dois grandes grupos, diversas classificações foram propostas por estudiosos desse campo com o propósito de particularizar questões que envolvem o processo sociocultural de atribuição de valor. Recentemente, estudos como os desenvolvidos pelo Getty Conservation Institute (GCI), compilados no livro intitulado Values in heritage management: emerging approaches and research directions (AVRAMI et al., 2019), refletiram sobre experiências de conservação pelo mundo cujas bases formuladoras foram os valores patrimoniais.

O caso do Parque Metropolitano Armando de Holanda Cavalcanti (PMAHC), no Cabo de Santo Agostinho, em Pernambuco, é representativo do conflito entre os atores envolvidos na valorização dos bens culturais e na escolha das alternativas de abordagem da gestão. Apesar de contemplada pela elaboração de vários planos e projetos, a conservação do Parque não se efetiva. Ao contrário, vivencia-se um ambiente permanente de tensão entre gestores, técnicos e residentes ${ }^{1}$, ao mesmo

\footnotetext{
1. Dentre os eventos mais recentes, destacam-se: o termo de ajuste de conduta (TAC) firmado entre moradores e gestores públicos (PERNAMBUCO, 2006); denúncias ao Ministério Público de Pernambuco pela ONG Fórum Suape (FÓRUM SUAPE, 2016); audiência pública sobre o PMAHC (CÂMARA MUNICIPAL DO CABO DE SANTO AGOSTINHO, 2019); e o Relatório Dhesca-Brasil (Direitos Humanos, Econômicos, Sociais, Culturais e Ambientais) sobre a violação de direitos na atuação do Complexo de Suape (DHESCA, 2018). PERNAMBUCO. Ministério Público Estadual. $3^{\text {a }}$ Promotoria de Justiça de Defesa da Cidadania do Cabo de Santo Agostinho. Termo de ajustamento de conduta, firmado entre o MPPE, O CIP-Suape, a Funcef, o município do Cabo de Santo Agostinho, a Agência Condepe/Fidem, a Fundarpe e a CPRH. Cabo de Santo Agostinho: MPPE, 2006. DHESCA BRASIL. Complexos industriais e violações de direitos: O caso de Suape - Complexo Industrial Portuário Governador Heraldo Gueiros. Relatório da missão de investigação e incidência. Brasília, DF: Dhesca Brasil, 2018.
} 
tempo que os bens culturais se degradam em consequência do descontrole urbano acentuado a cada dia.

Se os planos e projetos elaborados não conseguem atender às expectativas dos atores envolvidos, despontam duas indagações: i) em quais valores seus técnicos se basearam para definir as ações?; e ii) até que ponto tem sido efetiva a participação social para o dimensionamento dos valores e a formatação dos planos de gestão?

Para refletir sobre essas indagações, o artigo concentra-se na análise de documentos avaliativos e propositivos, elaborados para o Parque em três momentos: i) o processo de tombamento, tramitado no órgão estadual de gestão do patrimônio cultural, entre 1982 e 1983; ii) o Plano Estratégico, elaborado pelo órgão de planejamento metropolitano, em 2000, e iii) o Pacto por Suape Sustentável, elaborado por meio de uma cooperação técnica internacional entre o governo brasileiro, representado pela Agência Brasileira de Cooperação do Ministério das Relações Exteriores e pela Secretaria de Desenvolvimento do Estado de Pernambuco, e a Organização das Nações Unidas para a Educação, a Ciência e a Cultura (Unesco), em $2016^{2}$.

Como suporte à análise desses documentos, propõe-se uma breve reflexão sobre a conservação contemporânea, baseada nos valores patrimoniais, essenciais e instrumentais, seguida de uma síntese das missões institucionais dos órgãos envolvidos com a gestão do Parque. Esta última atividade contribuiu para a análise da participação dos entes no processo decisório.

\section{Da ênfase nos valores essenciais à instrumentalização do patrimônio}

A questão dos valores patrimoniais não é assunto novo nos estudos sobre a Conservação Integrada. A Carta de Veneza de1964 (1965) incorporou à conservação a noção de cultura e de sítio urbano, confirmada pela Declaração de Amsterdã (1975), e pela Carta de Burra, resultante do Encontro Internacional de Monumentos e Sítios Históricos, em 1979. Dessa forma, pode-se afirmar que a Conservação consolidou o redirecionamento da abordagem baseada nos valores. Os valores sociais ganharam importância, ao mesmo tempo que se revia a ênfase dada aos valores essenciais, relacionados à existência dos bens materiais (AVRAMI; MASON, 2019).

Ao utilizar o termo "significância cultural", a Carta de Burra (AUSTRÁLIA ICOMOS, 2013) incorporou definitivamente os "valores sociais” à conservação dos

2. O Pacto por Suape Sustentável envolveu investimentos no valor de R $\$ 1.288 .035,00$, sob a responsabilidade de Suape, com o objetivo de realizar estudos, propostas e capacitação, com vistas ao desenvolvimento socioambiental desse território. Os trabalhos foram executados por gestores de Suape e consultores contratados pela Unesco (SUAPE, 2018). 
bens culturais. Vivenciou-se um período de experimentação de processos mais participativos, com respeito à autenticidade, nos moldes relativistas e dinâmicos preconizados pela Carta de Nara (1994), e de incorporação de campos temáticos como o Planejamento Urbano, a Conservação Ambiental, a Política e o Direito.

A despeito do debate e do esforço dos profissionais do patrimônio para identificar uma gama mais ampla de valores, assim como de partes interessadas nas práticas de gestão, é possível afirmar que os avanços preconizados pela Carta de Burra foram, até pouco tempo, bastante tímidos. "Os processos formais de avaliação e conservação do patrimônio com base em valores não prevaleciam há décadas” (TEUTONICO, 2019, p. vii, tradução nossa). A partir do século XXI, os estudos econômicos sobre o patrimônio e os possíveis benefícios sociais, em decorrência de sua conservação, foram realizados com mais frequência. Desde então, a conservação baseada nos valores teve como foco de análise a instrumentalidade dos bens e sua relação com os valores tradicionais de existência.

Autores como Chris Caple (2000) e Randall Mason (2000) abordaram a necessidade de incorporar a exploração dos objetos patrimoniais à análise de valor. Caple (2000) direcionou sua análise às funções que o objeto patrimonial pode desenvolver na sociedade e às contribuições que pode dar na busca por soluções para os problemas contemporâneos das cidades. Mason (2000), por sua vez, atribuiu importante papel aos valores relacionados à utilidade dos bens e à sua capacidade como ativo econômico ${ }^{3}$. $\mathrm{O}$ autor relacionou dois grupos de valores: os consagrados valores socioculturais e os valores econômicos relativos à utilização dos bens e à sua inserção no mercado.

Entre 1998 e 2005, o Getty Conservation Institute desenvolveu um projeto de pesquisa com o intuito de estudar as abordagens econômicas e sociais do patrimônio e promover uma abordagem de Conservação Urbana mais sustentável. Foram realizados estudos sobre formas alternativas do patrimônio construído, noções de propriedade, viabilidade econômica, novas formas institucionais (parcerias público-privadas) e até a formação do profissional da conservação (AVRAMI; MASON, 2019, p. 19-20). Essa movimentação demonstrou a tendência do início do século e consolidou o princípio de que uma compreensão ampla da significância cultural deveria orientar todas as etapas da conservação, desde a identificação dos bens que constituem o patrimônio até a escolha das opções de intervenção, alocação de recursos, gestão e monitoramento das ações.

O esforço para compreender o novo papel atribuído aos valores também foi objeto de reflexão da pesquisadora Norma Lacerda (2012), do Centro de

3. Termo utilizado tal como nas Ciências Econômicas, representando o conjunto de bens com capacidade de gerar ganhos econômicos. 
Estudos Avançados da Conservação Integrada (CECI) da Universidade Federal de Pernambuco que, em 2012, publicou artigo sobre a temática, intitulado Valores dos bens patrimoniais. A autora propôs uma prática de conservação que leva em conta, de forma concomitante, os valores intrínsecos à existência do bem e os valores advindos de sua utilidade. Para ela, essa compreensão implica que qualquer intervenção não deve lastrear-se unicamente em cálculos econômicos - não desvirtuar a materialidade dos bens é igualmente importante. Nesse caso, a conservação pode explorar o valor de uso e o valor econômico dos bens enquanto constrói mecanismos que garantam sua transmissão: "Agindo de tal forma, não se compromete a sua existência” (LACERDA, 2012, p. 52).

Nesse mesmo sentido, Avrami e Mason construíram suas perspectivas acerca da dicotomia entre o que denominaram, por um lado, "valores patrimoniais" e, por outro, "valores sociais" (AVRAMI; MASON, 2019, tradução nossa). Para os autores, a primeira abordagem tem sido a dominante nas práticas de conservação. Ainda que se tenha avançado para ampliar a gama de valores e a forma de considerá-los, frequentemente os processos ficam restritos à abordagem de especialistas que se aferram a seus argumentos nas tomadas de decisão para atender ao objetivo "essencial” de preservação dos bens. A segunda abordagem atende a uma visão mais ampla de conservação, ao compreender o patrimônio como parte de uma produção social do espaço, envolta em interesses e disputas, com grande responsabilidade no tocante ao desenvolvimento sustentável dos lugares. Avrami e Mason (2019, p. 22, tradução nossa) ainda utilizaram os termos essenciais e instrumentais, numa apropriação dos conceitos formulados por Gamini Wijesuriya, Jane Thompson e Christopher Young, incorporados no Manual da Unesco (2013), para conceituar os "valores patrimoniais e sociais".

Avrami e Mason apontam limitações de uma abordagem conservadora baseada unicamente em "valores patrimoniais". Para eles, o foco exclusivo nesses valores culmina em práticas que buscam a proteção definitiva dos bens sem uma política de gestão posterior sustentada em valores sociais e que, portanto, considere a inserção dos bens na dinâmica social e urbana. Como as políticas dominantes, em geral, buscam garantir um "valor de opção" futuro, tem-se priorizado o registro de patrimônio, legando às gerações vindouras a responsabilidade por sua gestão (AVRAMI; MASON, 2019).

Nessa mesma direção, Buckley (2019, p. 53, tradução nossa) afirmou que o "valor social às vezes é mal interpretado como uma qualidade socioeconômica ou utilitária”, havendo uma tendência à adoção de práticas curatoriais.

Por outro lado, a crítica não se destina a menosprezar a importância desses valores. Ao contrário, a dinamicidade que os caracteriza pode levar a diferentes 
tomadas de decisão quanto à sua "utilização”. Em outras palavras, a Conservação ganhou responsabilidade como política pública, e a preservação de "valores patrimoniais” não pode ser encarada como "um fim em sim próprio”, uma vez que desempenha um importante papel no desenvolvimento social, econômico e político.

Nos últimos anos, a relação entre os bens patrimoniais e a sociedade evoluiu bastante. A discussão contemporânea posicionou o debate sobre os valores além da dicotomia entre valores de existência e valores de uso (LACERDA, 2012), valores patrimoniais e valores sociais, ou "valores essenciais e valores instrumentais" (AVRAMI; MASON, 2019). A forma como as comunidades participam do debate tornou-se mais ampla. Às práticas de conservação agregou-se a análise dos benefícios socioeconômicos dos cidadãos diretamente relacionados com os bens patrimoniais. Em virtude desse cenário, as experiências de conservação tornaram-se ainda mais complexas e conflituosas, precisando responder ao desafio de "sustentar os locais e ampliar a sua relevância” (AVRAMI et al., 2019, p. 1, tradução nossa).

No âmbito dos trabalhos do GCI, Kristal Buckley (2019) estudou a experiência de conservação australiana baseada nos valores patrimoniais. Assim como fizeram Zancheti e Hidaka (2014), a autora teceu críticas à Carta de Burra no que concerne à participação social nos processos de identificação dos valores. Para Buckley (2019), ao ampliar a gama de valores e inserir diversos atores no processo de identificação, a Carta de Burra deu pouca importância à participação social na gestão da conservação, desde a escolha das alternativas até a implementação e o monitoramento. Nesse caso, a Carta teria dado mais poder aos técnicos envolvidos com a gestão do patrimônio (BUCKLEY, 2019).

Kate Clark (2019) estudou as transformações na gestão do patrimônio no Reino Unido, à medida que os valores foram incorporados à prática de conservação. Ela fez suas reflexões explorando três tipos de valores: i) os valores "intrínsecos", relacionados à existência dos bens; ii) os valores "instrumentais", relacionados aos benefícios econômicos sociais e instrumentais; e iii) os valores “institucionais”, relacionados à forma como as instituições criam valor (CLARK, 2019). A pesquisadora concentrou seus estudos na influência que a missão institucional das entidades gestoras do patrimônio exerce sobre a abordagem da conservação. Para a autora, o objetivo principal das instituições é demonstrar o que elas fazem. Em outras palavras, a elas interessa apresentar dados que comprovem metas de desempenho, como locais preservados, recursos aplicados ou número de visitantes registrados (CLARK, 2019, p. 77). Em sítios habitados, como é o caso do objeto de estudo deste artigo, a depender dos objetivos institucionais da entidade gestora, os valores a serem preservados podem ser bastante distintos.

David Throsby (2019) trouxe contribuições ao tema da Conservação por meio de uma abordagem econômica que situa o patrimônio como ativo econômico, 
considerado então um capital cultural. Não raro, o conceito de "ativo" denota um valor financeiro. Diferentemente dessa abordagem, o "capital cultural incorpora ou dá origem a valores não monetários, atribuíveis aos fenômenos culturais” (THROSBY, 2019, p. 200, tradução nossa). Paralelamente, o autor associou o conceito de capital cultural ao capital natural, utilizado pela economia do meio ambiente. Segundo ele, há uma sinergia teórica entre os conceitos, de modo que as metodologias para avaliar o valor dos ativos ambientais e culturais são transferíveis de um para o outro (THROSBY, 2019, p. 201). Ao fim da análise, Throsby reconhece que a motivação para a maioria dos projetos de conservação se deve a razões culturais, e não ao desejo de ganho econômico. Por outro lado, ele argumenta que geralmente os projetos oferecem algum benefício que possa ser mensurado em termos financeiros. Com base nesse argumento, em face de o "não uso" interferir pouco na materialidade dos bens, o autor afirma ser "desejável que os benefícios econômicos desse valor sejam mensurados” (THROSBY, 2019, p. 204, tradução nossa).

Em síntese, percebe-se que a reflexão teórica contemporânea considera a interpretação dos valores patrimoniais essencial para a formulação das ações de conservação, reconhecendo o ambiente conflituoso no qual os diversos atores interessados no patrimônio fazem suas avaliações e escolhas. A dicotomia entre valor cultural e valor econômico tornou-se inescapável das práticas de conservação, seja na percepção dos valores, seja na escolha de alternativas.

\section{O PMAHC}

O PMAHC situa-se no litoral sul de Pernambuco, no município do Cabo de Santo Agostinho, integrante da Região Metropolitana do Recife (RMR). Seu reconhecimento formal se deu em 1979 e, em 1993, foi tombado pela Fundação do Patrimônio Histórico e Artístico de Pernambuco (Fundarpe), o órgão responsável pela gestão do patrimônio histórico, artístico e cultural do estado.

O território do PMAHC é repleto de edificações que contam a história do descobrimento do Brasil e das disputas entre portugueses e holandeses, na primeira metade do século XVII. Além disso, a região do Cabo de Santo Agostinho abriga afloramentos rochosos que comprovam a teoria da divisão do megacontinente de Gonduana, ocorrida há cerca de 102 milhões de anos, que resultou na abertura do oceano Atlântico e na formação dos continentes africano e americano (SIAL, 1976 apud GUIMARÃES, 2013). As paisagens naturais, de rara beleza, constituem-se em atrativos turísticos de abrangência nacional, como é o caso da praia de Calhetas.

Em área contígua à malha urbana da cidade, o PMAHC sofre constante pressão no que diz respeito à ocupação de seu território. A partir de meados de 2005, esse processo foi intensificado com o boom de desenvolvimento promovido pelo 
Complexo Industrial e Portuário de Suape (CIPS), que causou impactos na gestão do uso do solo em toda a região (DANTAS, 2013). Aos antigos moradores do local, somaram-se novos ocupantes, fazendo com que as construções irregulares se multiplicassem rapidamente.

A utilização do PMAHC como objeto empírico de análise da temática é bastante oportuna, uma vez que os planos e projetos de gestão não conseguiram, até o presente, conciliar os conflitos entre os atores envolvidos com o sítio patrimonial, tampouco promover a conservação do lugar, tanto para proteger os bens culturais como para incentivar o desenvolvimento local.

No centro do problema está a questão do controle urbano, que busca impedir a ocupação desordenada do território, impulsionada, sobretudo, pelo boom de crescimento resultante do Complexo Suape. Em 2018, durante reunião do Conselho Gestor do PMAHC, o Núcleo Administrativo do Parque (NAD) apresentou um quadro estatístico contemplando as denúncias de ações e obras irregulares por ele encaminhadas à Suape e à Prefeitura do Cabo de Santo Agostinho. Entre 2012 e 2017, o número de obras irregulares aumentou 817\% (CONSELHO GESTOR DO PMAHC, 2018, p. 3). Na ocasião, o NAD ainda relatou a ocorrência de pichações nas ruínas do Quartel e da Capela Velha de Nazaré, assim como a supressão de vegetação nativa, utilizada na construção de moradias.

Se, do ponto de vista material, as ações de controle urbano não têm conseguido desacelerar as ocupações desordenadas e os impactos decorrentes, no que se refere à relação com os moradores o clima de conflito tem se intensificado. Em 29 de maio de 2019, houve uma audiência pública na Câmara municípal (CÂMARA MUNICIPAL DO CABO DE SANTO AGOSTINHO, 2019) com o intuito de discutir as ações voltadas à conservação do Parque. Essas ações e o controle urbano foram os temas recorrentemente presentes nas falas de entidades e moradores, que demonstraram insatisfação e revolta. Na referida audiência, Sérgio Belo, morador da Vila Gaibu, no Cabo, assim se pronunciou: "Minha pauta é de construção, e pra isso temos que aprender a tratar os problemas sociais que estão ali dentro. As pessoas precisam ser tratadas com dignidade, precisam participar da construção das propostas e ter a visão do futuro do Parque” (BELO, 2019).

Em $1^{\circ}$ de agosto de 2019, em reunião do Conselho Gestor do Parque, Gercino Rocha, residente de Suape, proprietário de um pequeno restaurante, fez o seguinte comentário sobre uma recente operação de controle urbano na área: "Precisamos ser tratados com mais dignidade, com mais respeito. Peço que acabe com essas ações. Vamos conversar? Parecia mais que era o quê? Bandido!” (ROCHA, 2019). 
É nesse contexto que o Conselho Gestor do PMAHC busca soluções para minimizar os conflitos socioterritoriais e impulsionar ações de conservação que consigam proteger os bens e promover desenvolvimento.

\section{O Conselho Gestor e os atores envolvidos}

Em 2006, em virtude das inúmeras denúncias sobre o estado de conservação do Parque, o Ministério Público de Pernambuco intermediou um termo de ajustamento de conduta (TAC), com a finalidade de pôr em prática uma estrutura de gestão e definir as atribuições dos partícipes. Por meio do TAC, as partes pactuaram a criação de um conselho gestor, composto de um representante titular e de outro suplente de cada entidade, a saber:

- Suape, empresa pública, de direito privado, responsável pela gestão do Complexo Industrial e Portuário de Suape;

- PMCSA, Prefeitura Municipal do Cabo de Santo Agostinho;

- Funcef, Fundação dos Economiários Federais, que, devido a um termo de permissão de uso que objetivou a implantação de um complexo turístico/ hoteleiro na praia de Suape, teve como atribuição legal a gestão do Parque e a aplicação de investimentos;

- Condepe/Fidem, Agência Estadual de Planejamento e Pesquisas de Pernambuco, responsável pelo planejamento metropolitano;

- CPRH, órgão do governo do estado de Pernambuco responsável pela gestão do meio ambiente;

- Fundarpe, órgão do governo do estado de Pernambuco, vinculado à Secretaria Estadual de Cultura, responsável pela gestão do patrimônio cultural de Pernambuco;

- uma representação de moradores.

Ressalte-se a ausência do Instituto do Patrimônio Histórico e Artístico Nacional (Iphan), uma vez que essa instituição não tem atribuição de gestão do PMAHC, tombado em nível estadual pela Fundarpe. Mesmo assim, em virtude de o Povoado de Nazaré ser tombado em nível federal e situar-se dentro da área do Parque, o Iphan participa das reuniões do Conselho Gestor na condição de convidado.

Para compreender melhor os motivos da participação dos componentes do Conselho Gestor, importa destacar suas missões institucionais. Tendo em vista que a empresa Suape é proprietária das terras do Parque, é de esperar que seu papel seja relevante no processo de gestão local. Soma-se à sua capacidade de investimento o fato de as terras do Parque fazerem parte do Polígono do Complexo Industrial 
e Portuário do Estado, razão pela qual à Suape é atribuída a responsabilidade de viabilizar investimentos. Não por acaso, entre membros do Conselho Gestor, há consenso de que a empresa assuma a posição de presidência. Desde a formação do fórum colegiado de gestão, em 2006, nenhuma outra instituição ocupou essa função.

Segundo o site da própria empresa, a Suape tem por missão "Realizar a gestão das operações portuárias com segurança e eficiência e garantir a adequação da infraestrutura do Complexo Industrial Portuário, de forma sustentável, promovendo o ordenamento do território e atraindo investimentos que contribuam para o desenvolvimento do Estado de Pernambuco" (SUAPE, 2017).

Por natureza, cabe à Prefeitura Municipal do Cabo de Santo Agostinho a gestão da cidade. Sua atuação na gestão territorial do PMAHC se deve à existência de ocupação urbana, espontânea e desordenada. No Conselho Gestor, tem sido representada por técnicos dos setores de Controle Urbano e Ambiental, Planejamento Territorial, Turismo e Desenvolvimento Econômico.

Por outro lado, a Prefeitura questiona sua atribuição em agir no controle urbano na área do Parque, já que ela é de natureza privada, propriedade da empresa Suape. Mesmo assim, segue contribuindo com ações de controle urbano, visto que as ocupações desordenadas impactam na dinâmica urbana do município.

Do ponto de vista institucional, a Funcef, cujo estatuto vigente foi publicado em 2007, não tem nenhuma relação com a gestão do Parque. Trata-se de uma entidade fechada de previdência complementar, instituída pela Caixa Econômica Federal (CEF) em 1977, com a finalidade de administrar os planos de benefícios previdenciários de seus associados (FUNCEF, 2007), funcionários da CEF. A entidade assumiu um papel importante na gestão do Parque em 1990, quando decidiu investir em um complexo turístico e hoteleiro na praia de Suape e, em contrapartida à cessão de uma área para a implantação do empreendimento, ficou incumbida de alocar investimentos e gerir o Parque por 99 anos.

A Condepe/Fidem participa da gestão do Parque em decorrência de sua atuação no planejamento metropolitano. Até a implantação do Conselho Gestor, em 2006, a Condepe/Fidem dava à Suape o suporte necessário para planejar as ações no Parque.

A Fundarpe, órgão também vinculado ao governo do estado de Pernambuco, tem por finalidade "exercer a função de órgão executivo da política cultural do Estado de Pernambuco, promovendo, apoiando, incentivando e divulgando as atividades e manifestações culturais de Pernambuco" (PERNAMBUCO, 2007). Está presente na gestão do Parque desde sua institucionalização e tramitação do processo de tombamento (FUNDARPE, 1982), que, em nível estadual, é de sua competência. 
Além dos entes mencionados, outros participam das reuniões do Conselho apenas quando a pauta envolve assuntos relacionados às suas atribuições. É o caso da Universidade Federal de Pernambuco, que realiza pesquisas na área, do Exército brasileiro, proprietário das edificações militares, ou das concessionárias de serviços públicos, quando alguma questão exige posicionamento do Conselho Gestor.

Diante do exposto, é possível perceber que a gestão abrange moradores e diversos entes públicos e privados, cujos envolvimentos advêm de motivações distintas. Alguns, como é o caso da Funcef, além de não terem como missão institucional a gestão de patrimônio cultural, nem sequer tem funcionários com o perfil necessário para essa atribuição. Já a empresa Suape, de quem se esperam investimentos e a coordenação das ações, tem clara missão institucional associada ao desenvolvimento econômico do estado de Pernambuco, com responsabilidade sobre a atividade estratégica de gestão do porto e do complexo industrial a ele associado.

Nesse cenário, a análise das recentes propostas de intervenção elaboradas para o Parque contribui para a formulação de respostas à indagação a respeito de como a natureza dos entes gestores tem moldado a abordagem de gestão da conservação do Parque, que pode ser percebida nos planos e projetos analisados.

4. Os planos e projetos desenvolvidos

a) O processo de tombamento - 1982 a 1993

O processo de tombamento do Parque teve início em 18 de novembro de 1982. Para justificar a proposta, a Fundarpe apresentou um relato pormenorizado da ocupação do território, durante as navegações e batalhas luso-espanholas, e enalteceu os valores históricos e paisagísticos naturais do PMAHC. A proposta foi submetida ao Conselho Estadual de Cultura, composto de técnicos da Secretaria Estadual de Cultura. O Exame Técnico, documento em que se emitiu o parecer final, julgou pertinente o tombamento, fundamentando-se na "importância indiscutível do Sítio Histórico" e nas "construções e ruínas de carácter excepcional existentes na área" (FUNDARPE, 1982, p. 135).

Durante as considerações que deram sustentação ao parecer, o Exame Técnico exaltou características paisagísticas naturais do Parque e demonstrou preocupação com os possíveis impactos advindos da implantação do Porto de Suape (FUNDARPE, 1982, p. 135).

A Resolução no 2/93 do Conselho Estadual de Cultura oficializou e deu publicidade ao tombamento. Além disso, reafirmou os valores históricos, artísticos e paisagísticos do Parque e apresentou recomendações que são relevantes para nossa análise, tendo em vista que as propostas apresentadas, reflexo da abordagem de conservação adotada naquele momento, resultaram do processo de mensuração dos valores. 
As recomendações coadunam-se com a fundamentação da proposta de tombamento e do Exame Técnico. Dentre elas, predominaram ações de proteção dos bens, na forma de estabilização de ruínas, restauro e vigilância (FUNDARPE, 1982, p. 137-138). Naquele momento, a valorização da essencialidade dos bens e a consequente abordagem de gestão protecionista nortearam as ações.

b) O Plano Estratégico do PMAHC - 2000

O Plano Estratégico do PMAHC foi elaborado em 2000, produto de um convênio interinstitucional, firmado entre os órgãos envolvidos com a gestão do PMAHC. Teve como finalidade "instaurar um processo permanente de planejamento e ser instrumento de pressão política para promover o cumprimento dos seus objetivos” (PERNAMBUCO, 2000, p. 1).

Elaborado por um corpo técnico de consultores contratados por órgãos públicos (Condepe/Fidem e Fundarpe), o Plano Estratégico avaliou os valores do Parque de forma semelhante ao que foi feito no processo de tombamento, enaltecendo seus atributos físicos, naturais e construídos (PERNAMBUCO, 2000, p. 20-21).

Diferentemente da abordagem constatada no processo de tombamento, à ênfase nos valores essenciais dos bens culturais associou-se a expectativa de sua exploração com vistas a promover o desenvolvimento local. Nesse caso, a abordagem de gestão mostrou-se notadamente exploratória, voltada à instrumentalidade do patrimônio, refletindo-se em objetivos estratégicos vinculados ao fomento da atividade turística no local (PERNAMBUCO, 2000, p. 30-34).

c) O projeto Pacto por Suape Sustentável

Em 2016, com o propósito de minimizar os impactos negativos do crescimento do Complexo Industrial e Portuário de Suape, o governo do estado de Pernambuco firmou uma parceria de cooperação técnica com a Unesco, denominada Pacto por Suape Sustentável, com o objetivo de "contribuir para a sistematização de ações estratégicas em SUAPE, com vistas ao desenvolvimento socioambiental sustentável da região" (SUAPE, 2018, p. 10).

O projeto foi estruturado de modo a atingir três objetivos imediatos: o primeiro, de caráter situacional, previa sistematizar estudos das vulnerabilidades e necessidades ambientais, sociais, educacionais, culturais e legais da região; o segundo, de caráter propositivo, intentava subsidiar a elaboração de um plano de ação estratégico com projetos para solucionar as fragilidades existentes; e o terceiro, abordando a gestão compartilhada, propunha capacitar e sensibilizar equipes técnicas de Suape e do município do Cabo de Santo Agostinho, assim como comunidades locais e empresas para a cogestão e o fortalecimento dos protagonismos em 
busca de recursos para ações na área (SUAPE, 2018, p. 9). Além de algumas ações previamente estabelecidas, o terceiro objetivo seria alcançado sobretudo pela inserção dos entes envolvidos no processo de diagnóstico e construção de propostas (SUAPE, 2018, p. 166-169). Previa-se, então, “o fortalecimento geral da autogestão comunitária e gestão pública em projetos de educação, qualificação profissional, cultural e gestão ambiental” (SUAPE, 2018, p. 20).

De maneira análoga ao que se constatou no Plano Estratégico - 2000, as propostas apresentadas pelo projeto enfatizaram a possibilidade de exploração dos seus bens. Além disso, a abordagem concentrou-se nos atributos do patrimônio natural, explorados em função da repercussão favorável que as ações de preservação ambiental conseguem promover junto à população. O projeto propôs a criação da Unidade de Conservação Monumento Natural Armando de Holanda Cavalcanti (MONAHC), justificada pela necessidade de integrar uma rede de unidades de conservação no território do CIPS, de maneira que se viabilize o recebimento de recursos obtidos com o Pagamento de Serviço Ambiental (PSA) por parte das empresas instaladas no Complexo.

O Plano de Gestão para o MONAHC apresentou projetos agrupados, no que se denominou Programa de Manejo, e seguiu o que estabelece o Plano Diretor Suape 2030, na direção de favorecer a realização de ações de responsabilidade socioambiental e cultural e de minimizar os efeitos negativos decorrentes da dinamização econômica da região (SUAPE, 2018, p. 37).

A preocupação em associar responsabilidade socioambiental à imagem da empresa Suape e das demais empresas instaladas no CIPS foi um aspecto relevante no projeto. Essa iniciativa justifica-se pelos reconhecidos efeitos negativos das atividades econômicas desenvolvidas pelas empresas, que impactam negativamente a reputação dos envolvidos. O Relatório Final da cooperação esforçou-se em valorizar a repercussão do projeto nas mídias locais e nacionais. Nesse sentido, deu ênfase à publicação de um artigo científico internacional, intitulado "Suape/Brasil: impactos no perfil socioeconômico na envolvente do complexo industrial e portuário” (LOPES; MALAFYA; REGO, 2016), assim como a matérias jornalísticas digitais e impressas.

A midiatização do convênio também está presente no discurso do governador de Pernambuco, proferido em cerimônia de lançamento da parceria com a Unesco. Disse o governador:

[...] Nós estamos, mais uma vez, dando um passo concreto no fortalecimento da sustentabilidade no nosso estado. Já tínhamos uma preocupação para que esse desenvolvimento econômico que ocorreu nos últimos anos fosse acompanhado da garantia de políticas sociais 
e um meio ambiente protegido [...] Suape tomou todas as precauções para que chegássemos a esse momento, a partir de toda a compensação ambiental feita nos últimos anos [...] (SUAPE, 2016, grifos nossos).

A participação social no processo de elaboração do projeto é uma questão que merece destaque. Em virtude da presença da Unesco, por meio de consultores contratados, assim como do escopo dos serviços que no terceiro objetivo imediato previa sensibilização e capacitação para participação na gestão do Parque, esperava-se que a tensão entre gestores e residentes arrefecesse. Entretanto, a inserção da população residente ficou restrita ao papel de fonte de informações, sem nenhuma participação efetiva no processo de escolha de alternativas ou de tomada de decisão.

No final de 2016, o Fórum SUAPE, organização não governamental que atua na região com foco na área de direitos humanos, encaminhou uma carta à Direção Geral da Unesco, questionando sua atuação. Lê-se num trecho da referida carta:

[...] o Fórum Suape solicita que a Unesco revise a execução do termo de colaboração técnica, no intuito de salvaguardar a coerência com a sua sólida história e missão, como Agência da ONU [...] A natureza desse Prodoc e a associação entre Unesco e CIPS constitui matéria de preocupação e interesse da sociedade civil e requer uma rápida resposta (FÓRUM SUAPE, 2016).

Apesar das manifestações adversas à gestão do Parque e ao processo de elaboração dos produtos, objeto do Acordo de Cooperação entre Unesco e Suape, em 20 de março de 2018, o Relatório Final do Acordo foi apresentado em reunião do Conselho Gestor do PMAHC. Ressalta-se a ausência de qualquer representante da comunidade nessa reunião, o que foi destacado pelos representantes da Fidem e da Fundarpe (CONSELHO GESTOR DO PMAHC, 2018, p. 1).

\section{Considerações finais}

A Conservação Urbana tem sido intimada a dar respostas aos problemas urbanos das cidades contemporâneas. A conservação dos bens culturais não se apoia unicamente nos valores essenciais, relacionados ao registro histórico ou à garantia de sua existência para que as gerações futuras tenham a opção de atribuir seus próprios valores. Os investimentos e os esforços empenhados pelos diversos atores envolvidos com o sítio patrimonial somente se justificam quando os bens são instrumentalizados, com base tanto em valores sociais como econômicos. Por outro lado, a partir do momento em que se deu maior ênfase aos valores sociais e se 
ampliou a diversidade de participantes nos processos decisórios, a gestão do patrimônio cultural urbano tornou-se ainda mais complexa.

Entre valores essenciais, em geral exaltados por técnicos e especialistas que atuam na salvaguarda de bens culturais, e valores instrumentais, costumeiramente celebrados por gestores públicos que almejam os benefícios advindos da exploração dos bens, ou mesmo pela população residente, percebe-se que, além da dualidade das abordagens, a gestão da conservação é repleta de conflitos inerentes à atribuição de valores e à apropriação dos bens pelos envolvidos com o patrimônio. Nesse contexto, independentemente das alternativas de conservação, para obter êxito na proteção dos bens patrimoniais e na minimização dos conflitos, há que se alinhar os discursos com as realidades locais, garantindo a efetiva participação de todos aqueles que integraram o processo de planejamento, inclusive as comunidades locais.

Num primeiro momento, o processo de tombamento do Parque, cuja proposta e análise ocorreram exclusivamente em fórum técnico, culminou na ênfase sobre os valores essenciais dos bens materiais e numa proposta protecionista. Portanto, não se pode negar que as escolhas, alheias à visão das comunidades residentes, contribuíram para o insucesso da conservação. Nem mesmo o controle urbano conseguiu ser eficiente.

Na sequência, o Plano Estratégico do PMAHC-2000, também formatado no âmbito técnico de uma consultoria especializada, focou na instrumentalidade dos bens e na sua exploração econômica pela indústria do turismo. A proposta coaduna-se com as expectativas de desenvolvimento, apoiadas no patrimônio, que vigoravam no debate sobre o patrimônio cultural. Tampouco no Plano Estratégico as comunidades foram ouvidas. A despeito disso, a não execução do Plano parece mais ser resultado da falta de alocação de recursos financeiros do que de conflitos sobre as ações escolhidas.

Por fim, o projeto Pacto por Suape Sustentável revelou que a empresa Suape, responsável pela gestão do território, tem enfatizado a importância do patrimônio como forma de mitigar a repercussão negativa das atividades econômicas desenvolvidas no CIPS. Ou seja, os resultados práticos da conservação do lugar importam menos do que a repercussão social alcançada pela divulgação das ações de conservação. Não por acaso, o Projeto concentrou-se em valores do patrimônio natural, priorizando ações relacionadas à preservação dos ecossistemas e destacando mecanismos de compensação ambiental.

O Projeto foi no sentido contrário às recomendações mais recentes, fundamentadas em práticas bem-sucedidas. Conduzido unilateralmente pela empresa 
Suape, ignorou a participação dos entes que compõem o Conselho Gestor, que só tomou conhecimento do produto final do projeto 24 meses após sua elaboração. Apesar da cooperação da Unesco, que deu visibilidade à iniciativa, o Projeto sofreu várias críticas das comunidades e organizações sociais pelo fato de não ter permitido a participação das representações sociais.

Os documentos analisados demonstraram a ausência total de participação social nos processos decisórios, quer na atribuição dos valores, quer na formatação das ações. Desde o processo de tombamento do Parque, as comunidades residentes foram ignoradas e os grupos sociais só foram utilizados como fonte de dados. Predominou o pensamento dos técnicos da conservação, voltado à preservação de valores históricos e arquitetônicos. Porém, no projeto Pacto por Suape Sustentável, elaborado por consultores da Unesco em 2016, revelou-se desconformidade com o que se espera dos processos de conservação contemporâneos, que levam em conta a diversidade de atores e de interesses, ampla participação social, respostas aos problemas urbanos e sociais e preservação dos bens.

A Conservação Urbana, baseada nos valores patrimoniais, ainda enfrenta questões relevantes sobre o equilíbrio entre a ênfase no passado e a instrumentalidade do patrimônio, como ativo para responder às necessidades presentes da sociedade. Por mais que os valores patrimoniais tenham sido incorporados nas estruturas de gestão, o debate sobre as formas como são racionalizados, com a estruturação das políticas públicas, ainda necessita ser aprofundado. Além do contexto sociocultural e urbano, a missão das instituições que cada sujeito representa, às quais desejam permanecer vinculados, influencia fortemente a formulação dos planos de conservação apoiados em valores patrimoniais.

Além disso, a participação social nos processos decisórios deixou de ser uma hipótese - na atualidade, é condição para a formatação dos planos de ações. Ela deve acontecer não apenas como fonte de informação, mas também na avaliação dos cenários e na formatação das ações. Assim como no caso em estudo, as práticas de conservação que ignoram esse aspecto não têm conseguido minimizar os conflitos socioterritoriais inerentes à conservação do patrimônio cultural.

\section{Referências}

AUSTRÁLIA ICOMOS. The Burra Charter: The Australia ICOMOS Charter for Places of Cultural Significance. Burra: ICOMOS, 2013.

AVRAMI, E. et al. Values in heritage management: emerging approaches and research directions. Los Angeles: The Getty Conservation Institute, 2019. 
AVRAMI, E.; MASON, R. Mapping the issue of values. In: AVRAMI, E. et al. Values in heritage management: emerging approaches and research directions. Los Angeles: The Getty Conservation Institute, 2019. p. 9-33.

BELO, S. Depoimento. Cabo de Santo Agostinho: Câmara Municipal do Cabo, 30 maio 2019. Notícias [web]. Disponível em: https://www.cabodesantoagostinho.pe.leg.br/institucional/noticias/parque-metropolitano-armando-de-holanda-e-tema-de-audiencia-na-camara. Acesso em: 6 set. 2019.

BUCKLEY, K. Heritage work: understanding the values, applying the values. In: AVRAMI, E. et al. Values in heritage management: emerging approaches and research directions. Los Angeles: The Getty Conservation Institute, 2019. p. 50-65.

CÂMARA MUNICIPAL DO CABO DE SANTO AGOSTINHO. Parque Metropolitano Armando de Holanda é tema de audiência na Câmara, 30 maio 2019. Notícias [web]. Disponível em: https://www.cabodesantoagostinho.pe.leg.br/institucional/noticias/parque-metropolitano-armando-de-holanda-e-tema-de-audiencia-na-camara. Acesso em: 6 set. 2019.

CAPLE, C. Conservation skills: judgement, method and decision making. Abingdon: Routledge, 2000.

CLARK, K. The shift toward values in UK heritage practice. In: AVRAMI, E. et al. Values in heritage management: emerging approaches and research directions. Los Angeles: The Getty Conservation Institute, 2019. p. 66-82.

CONSELHO DA EUROPA. Declaração de Amsterdã de 1975. Tradução: Instituto do Patrimônio Histórico e Artístico Nacional. Brasília, DF: Iphan, [s.d.]. Disponível em: http://portal. iphan.gov.br/uploads/ckfinder/arquivos/Declaracao\%2ode\%20Amsterda\%CC\%83\%20 1975.pdf. Acesso em: 30 jun. 2017.

CONSELHO GESTOR DO PMAHC (Cabo de Santo Agostinho). Ata da reunião ordinária, 20 de março de 2018. Cabo de Santo Agostinho, 2018.

DANTAS, R. Suape: uma joia lapidada há quatro décadas. Desenvolvimento, [S.l.], 29 mar. 2013. Disponível em: https://pedesenvolvimento.com/2013/03/29/suape-uma-joia-lapidada-ha-quatro decadas/. Acesso em: 19 jan. 2018.

FÓRUM SUAPE. Fórum se reúne com representante da Unesco em Suape. Fórum em Ação, ${ }^{\circ}$ 1, jul. 2016. Disponível em: http://forumsuape.ning.com/profiles/blogs/forum-em-acao-edicao-de-julho-de-2016. Acesso em: 18 fev. 2019.

FUNCEF. Portaria no 1.349, 31 de junho de 2007. Estatuto da Fundação dos Economiários Federais. Diário Oficial da União, Brasília, DF, $1^{0}$ ago. 2007. Disponível em: https://www. funcef.com.br/files/estatuto_versao_2012_online.pdf. Acesso em: 22 set. 2020.

FUNDARPE. Processo de tombamento 166/1982: Sítio Histórico do Cabo de Santo Agostinho. Recife: Fundarpe, 1982. Arquivos digitais.

GUIMARÃES, T. de O. Geoconservação: mapeamento, descrição e propostas de divulgação de trilhas geoturísticas no Parque Metropolitano Armando de Holanda Cavalcanti, Cabo de Santo Agostinho-PE, Brasil. 2013. 154 f. Dissertação (Geociências) - Centro de Tecnologia e Geociências, Universidade Federal de Pernambuco. Recife, 2013.

ICOMOS. The Nara Document on Authenticity. Paris: Icomos, 1994. Disponível em: https://www.icomos.org/charters/nara-e.pdf. Acesso em: 2 fev. 2019. 
ICOMOS. The Venice Charter for the conservation and restoration of monuments and sites (The Venice Charter 1964). Paris: Icomos, 1965. Disponível em: https://www.icomos.org/ charters/venice_e.pdf. Acesso em: 24 maio 2012.

LACERDA, N. Valores dos bens patrimoniais. In: LACERDA, N.; ZANCHETI, S. (org.). Plano de Gestão da conservação: conceitos e métodos. Recife: Centro de Estudos Avançados da Conservação Integrada, 2012. v.1, p. 44-54.

LOPES, D.; MALAFYA, F.; RÊGO, M. Suape/Brasil: impactos no perfil socioeconômico na envolvente do complexo industrial e portuário. Focus, Veneza, n. 32, n.p., dez. 2016. Disponível em: https://portusonline.org/pt/suape-pebrasil-impacts-on-the-socio-economic-profile-in-the-surroundings-of-the-industrial-and-port-complex/. Acesso em: 2 fev. 2020.

MASON, R. Assessing values conservation planning: methodological issues and choices. In: TORRE, M. de la. Assessing the values of cultural heritage. Los Angeles: The Getty Conservation Institute, 2000.

PERNAMBUCO. Plano Estratégico do Parque Metropolitano Armando de Holanda Cavalcanti. Recife: Fidem; Fundarpe; CPRH; Suape; Fade, 2000.

Decreto no 30.391, de 27 de abril de 2007. Aprova o Regulamento da Fundação do Patrimônio Histórico e Artístico de Pernambuco - FUNDARPE, e dá outras providências. Diário Oficial Eletrônico, Recife, PE, 28 abril 2007. Disponível em: https://legis.alepe.pe.gov.br/texto.aspx?tiponorma $=6 \&$ numero $=30391 \&$ complemento $=0 \& a n o=2007 \&$ tipo=\&url=. Acesso em: 22 set. 2020.

ROCHA, G. Depoimento. Reunião do Conselho Gestor do PMAHC. Cabo de Santo Agostinho, 2019. Arquivo mpeg. Acervo de Paulo Cunha.

SUAPE. Parceria com a Unesco e a ABC impulsiona ações em Suape. Notícias [web Suape]. 13 mar. 2016. Disponível em: http://www.suape.pe.gov.br/pt/noticias/782-parceria-com-a-unesco-e-a-abc-impulsiona-acoes-em-suape. Acesso em: 10 fev. 2018.

Missão, visão e valores. Mapa estratégico organizacional 2017-2023. Ipojuca: Suape, 2017. Disponível em: http://www.suape.pe.gov.br/pt/institucional/missao-visao-e-valores. Acesso em: 22 set. 2020.

Relatório final da cooperação técnica entre o governo brasileiro e a Organização das Nações Unidas para a Educação, a Ciência e a Cultura. Ipojuca: Unesco, 2018. 270 p.

TEUTONICO, M. J. Prefácio. In: AVRAMI, E. et al. Values in heritage management: emerging approaches and research directions. Los Angeles: The Getty Conservation Institute, 2019. p. vii-viii.

THROSBY, D. Heritage economics: coming to terms with value and valuation. In: AVRAMI, E. et al. Values in heritage management: emerging approaches and research directions. Los Angeles: The Getty Conservation Institute, 2019. p. 199-209.

UNESCO. Managing cultural world heritage: Manual resouce. Paris: United Nations Educational, Scientific and Cultural Organization, 2013. Disponível em: https://whc. unesco.org/en/managing-cultural-world-heritage/. Acesso em: 5 jan. 2020.

ZANCHETI, S.; HIDAKA, L. A declaração de significância de exemplares da arquitetura moderna. Olinda: Centro de Estudos da Conservação Integrada, 2014. 


\section{Paulo José de Albuquerque Marques da Cunha}

Arquiteto e urbanista pela Universidade Federal de Pernambuco (UFPE), mestre em Gestão de Políticas Públicas pela Escola de Governo Fundação Joaquim Nabuco (Fundaj) e doutorando pelo Programa de Pós-graduação em Desenvolvimento Urbano da UFPE. Professor do Instituto Federal de Educação, Ciência e Tecnologia de Pernambuco (IFPE). Vice-líder do grupo CNPq/UFPE (Laboratório de Estudos Periurbanos) e do grupo CNPq/IFPE (Laboratório de Estudos Socioambientais). Áreas de pesquisa: conservação urbana integrada, gestão de políticas públicas, planejamento territorial, patrimônio cultural, memória e identidade.

Email: arqpaulocunha@gmail.com

ORCID: 0000-0003-1149-7019

Contribuição de autoria: conceituação; curadoria de dados; análise formal; investigação/pesquisa; metodologia; escrita - primeira redação; revisão e edição.

\section{Tomás de Albuquerque Lapa}

Arquiteto e urbanista pela Universidade Federal de Pernambuco (UFPE), mestre em Gestão de Políticas Públicas pela Escola de Governo Fundação Joaquim Nabuco (Fundaj) e doutorando pelo Programa de Pós-graduação em Desenvolvimento Urbano da UFPE. Professor do Instituto Federal de Educação, Ciência e Tecnologia de Pernambuco (IFPE). Vice-líder do grupo CNPq/UFPE (Laboratório de Estudos Periurbanos) e do grupo CNPq/IFPE (Laboratório de Estudos Socioambientais). Áreas de pesquisa: conservação urbana integrada, gestão de políticas públicas, planejamento territorial, patrimônio cultural, memória e identidade.

Email: thlapa@hotmail.com

ORCID: 0000-0003-1763-1004

Contribuição de autoria: conceituação; análise formal; metodologia; supervisão/ orientação; escrita - primeira redação; revisão e edição. 
Submissão: 20 de junho de 2020.

Aprovação: 3 de fevereiro de 2021.

Como citar: CUNHA, P. J. A. M.; LAPA, T. A. Entre a essencialidade e a instrumentalidade do patrimônio: valores institucionais e participação social na gestão da conservação urbana. Revista brasileira de estudos urbanos e regionais. v. 23, E202109, 2021. DOI 10.22296/2317-1529.rbeur.202109

Artigo licenciado sob Licença Creative Commons CC BY 4.0.

https://creativecommons.org/licenses/by/4.o/deed.pt_BR 